\title{
Changes in University Students' Explanation Models of DC Circuits
}

\section{Kokkonen, Tommi}

2018-08

Kokkonen , T \& Mäntylä , T 2018 , ' Changes in University Students' Explanation Models of

DC Circuits ' , Research in Science Education , vol. 48 , no. 4 , pp. 753-775 . https://doi.org/10.1007/s11165-016-958

http://hdl.handle.net/10138/308018

https://doi.org/10.1007/s11165-016-9586-y

acceptedVersion

Downloaded from Helda, University of Helsinki institutional repository.

This is an electronic reprint of the original article.

This reprint may differ from the original in pagination and typographic detail.

Please cite the original version. 
Changes in University Students' Explanation Models of DC circuits

\author{
Tommi Kokkonen \\ Dept. of Physics, University of Helsinki, Finland \\ $\&$ \\ Terhi Mäntylä \\ School of Education, University of Tampere, Finland
}

This is a post-peer-review, pre-copyedit version of an article published in Research in Science Education. The final authenticated version is available online at: http://dx.doi.org/10.1007/s11165-016-9586-y 


\section{Introduction}

Learning physics concepts is a demanding and lengthy process. One well-known learning obstacle is that students' own conceptions or intuitive knowledge differ from scientific knowledge, sometimes even conflicting with it. Moreover, these conceptions often remain unchanged even after instruction. A number of studies in science education research have addressed students' initial knowledge and its transformation through instruction (see, e.g., Perkins \& Grotzer, 2005; Slotta \& Chi, 2006; Vosniadou, 2002; Wiser \& Amin, 2001). These studies often portray students' knowledge at different levels of knowledge, such as beliefs, ideas, mental models and underlying frameworks (Amin, Smith, \& Wiser, 2014), which are often linked to different learning processes (Chi, 2008; Vosniadou, 2002).

Many previous studies have focused on the role of students' ontologies and processes related to ontological change, as well as the role of macro-level knowledge in relation to micro-level knowledge in switching between ontological categories $^{1}$ (Chi, Slotta \& de Leeuw, 1994). In addition to recognising the central role of ontological shift, researchers have pointed out that students often use simple, linear, causal thinking and experience difficulty grasping the complex relational structures of scientific theories (Chi, 2013; Perkins \& Grotzer, 2005).

${ }^{1}$ Chi et al. (1994) posit that "entities in the world may be viewed as belonging to different ontological categories" such as matter, mental states or processes (p.28), Consequently, students' ontologies can be described as knowledge of "what kind of entities there are in the world" (Amin et al, 2014, p.59). 
The specific context of this study is learning concepts about electric current, voltage and resistance within direct current circuits. Previous research has shown that students hold numerous misconceptions and false models of DC circuit concepts (Borges \& Gilbert, 1999; Lee \& Law, 2001; McDermott \& Shaffer, 1992; Shipstone, 1988). Many of the difficulties can be attributed to difficulty with the ontological shift. However, some researchers have questioned whether ontological shift is the main problem in learning in this specific context (see, e.g., Gupta, Hammer \& Redish, 2010; Vosniadou \& Skopeliti, 2014). The results discussed here show that such caution is indeed warranted, and that an important part of learning, at least in the advanced stages, can be attributed to greater proficiency in using the theory as a basis for model construction, rather than to ontological shift. Model construction is highly relevant in building the meaning of concepts and augmenting their context of applicability by providing relational knowledge between them (see, e.g., Andersen \& Nersessian, 2000; Nersessian, 2008).

The approach in the current study rests on the recently suggested means of understanding students' knowledge known as the "systemic approach" or "systemic view" (Koponen \& Kokkonen, 2014, p.141). This view represents the knowledge as comprising multiple interacting elements in an attempt to embed them into a single model (Brown \& Hammer, 2008; Koponen \& Kokkonen, 2014;). At the level of scientific concepts, we use the dynamic frames view, according to which both theoretical, law-like relations and ontological status are central to concept development (see Andersen, Barker \& Xiang, 2013; Andersen \& Nersessian, 2000). As a contextualised example, we first discuss students' 
understanding of the concepts of electric current and voltage as they are related to DC circuit phenomena, and second, bridge this understanding with a discussion about the structure and development of scientific knowledge.

A convenient representation of students' knowledge, which focuses on relational aspects of knowledge (relations between concepts and among concepts and other elements of the knowledge system), is based on the directed graph model (DGM) recently introduced by Koponen and Kokkonen (2014). This study focuses on students' explanations, their use of explanation models and the models' relation to concepts, as well as on the development of scientific concepts through the development of these relations. The empirical data consist of videorecorded group interviews of university students solving problems related to DC circuits. This is a context of advanced learning, which contrasts sharply with previous studies in which ontological shift is central. In the present case, instead of ontological shift, theoretical knowledge and ability in using it become more important in learning the concepts. Hence, the specific subject of interest in students' knowledge is the types of relations they used. Their ability to apply and modify the relational aspects of conceptual knowledge appears to be the key element in successfully constructing explanation models for the tasks presented to them. Therefore, the results provide a further step towards understanding the complexities of the learning process, building on completed ontological shift and progressing further towards scientific knowledge. 


\section{Learning Scientific Concepts}

Ontological attributions of concepts

Research in science education has found that concepts such as heat, electric current or force carry different meanings for students than for scientists. Students, for example, often conflate closely related concepts and fail to understand them as different; differentiation of the concepts is therefore incomplete. Common examples include electric current and voltage (Lee \& Law, 2001; McDermott \& Shaffer, 1992), heat and temperature (Wiser \& Amin, 2001) and weight and density (Smith, Carey \& Wiser, 1985). Sometimes students use the terms voltage and current interchangeably or explicitly understand voltage as a synonym for current (McDermott \& Shaffer, 1992; Reiner et al., 2000). Voltage is also sometimes understood as the intensity or force of a current or as the amount of current stored in a battery (Reiner et al., 2000).

The above difficulties reflect not only terminological confusion but also a more profound lack of understanding of the phenomena. Moreover, they result from a gap between everyday and scientific reasoning. Scientific concepts are abstract, often referring to categories that are purely conceptual (such as models) (Andersen et al., 2013), yet students' concepts are likely to have the characteristics of material objects. For example, many naive conceptions of electricity and electric current in particular are associated with substance-like conceptions (Reiner et al., 2000) - especially the widely reported conception about battery as a source or storage of electricity, which is then consumed in 
bulbs (see, e.g., Borges \& Gilbert, 1999; Koumaras, Kariotoglou \& Psillos, 1997; McDermott \& Shaffer, 1992). Similarly, students often conceive voltage as a substance (Reiner et al., 2000).

Some researchers have argued that the above difficulties arise from misconceived ontologies. Studies along this line have found that learning is particularly difficult whenever it requires an ontological shift from conceiving electric current as matter to understanding it as a process (Amin et al., 2014; Chi, 2013; Chi et al., 1994; Slotta, Chi \& Joram, 1995). This shift has been conceptualised as the shift in attributions students associate with the concepts (Chi, 2013; Chi et al., 1994; Slotta et al., 1995). Thus, the substance-based concepts would be associated with attributes such as "pushable", "containable" or "locational" (Reiner et al., 2000, p.5). A shift to a process ontology would link the concept to attributes such as "is an hour long", "is caused by" or "is in equilibrium" (Chi et al., 1994, p.29). Differentiating two closely related concepts (e.g. current and voltage) would then mean assigning two distinct sets of attributes to the concepts so that students understand them as different concepts.

Relational structures between concepts

Even after completing an ontological shift, further learning related to different relational structures between concepts must often take place. In science, and especially in physics, explanations of phenomena nearly always involve two or more concepts and some regularities in their covariation (Andersen \& Nersessian, 2000; Andersen et al., 2013). These patterns of covariation are 
known as laws or models. ${ }^{2}$ Such relations are vital to understanding the concepts and how to use them. Indeed, only when concepts are used in a law-like, relational structure are their meanings and roles unambiguously defined and the concepts understood as different. However, students are often unaware of the various relational patterns included in models. Instead, they are inclined towards simple linear reasoning with sequential chains of causes and effects (e.g. A causes B) and are unaware of more complex patterns such as constraint-based interactions $^{3}$ (De Bock, Van Dooren \& Verschaffel, 2011; Perkins \& Grotzer, 2005). Perkins and Grotzer (2005) have argued that many misconceptions are rooted in students' insufficient causal repertoire. Thus, the kind of "sequential" thinking associated with the belief of consumability of current is interpreted as a lack of proper causal schemes. Students fail to grasp the relevant causal structure associated with scientific knowledge. Problems may also be related to misconceiving the nature of causal relations. ${ }^{4}$

In summary, in explaining phenomena, two or more scientific concepts are used together in the form of models. This is an area often discussed from the viewpoint of model construction or model-based learning, but seldom connected directly with concept learning (for a notable exception, see Nersessian, 1995).

\footnotetext{
${ }^{2}$ Here we avoid discussing differences in covariation in models and laws (for a discussion adapted to science education, see Koponen (2007)).

${ }^{3}$ As an example, consider Ohm's law $\mathrm{U}=\mathrm{RI}$, relating current, voltage and resistance, or $\mathrm{Q}=\mathrm{C} \Delta \mathrm{T}$, relating heat and change in temperature through heat capacity.

${ }^{4}$ Note that the relations are not always causal. It is possible to view the relational structure as constraining laws or covariation of concepts in the form of constrained determination.
} 
Scientific concepts

Any study that explores the learning of scientific concepts needs to bridge the gap between theories of students' personal knowledge and theories of scientific knowledge. To this end, a view of scientific theories by Andersen and her colleagues known as the dynamic frames view is suitable, since it discusses the meaning and learning of scientific concepts from a cognitive point of view, thus providing a contact point with the conception of knowledge in learning (see Andersen et al., 2013; Andersen \& Nersessian, 2000). The dynamic frames view also focuses on the relational structure of concepts and notes that concepts cannot be learned in isolation. Whereas everyday concepts such as goose or swan are learned through contrasting similarities, scientific concepts are not learned in this way (Andersen et al., 2013; Hoyningen-Huene, 1993). We cannot point out the concept of mass, for example, or compare it to contrasting instances. Rather, we learn these scientific concepts essentially through their relations to other concepts (in the case of mass, one obvious relation is Newton's second law, $F=m a$; thus, learning occurs in situations where these three concepts appear together).

According to the dynamic frames view, concept learning involves a categorisation process (Andersen et al., 2013). We often learn scientific concepts through solving problems; we must apply concepts as parts of models (and/or laws). When learning to solve novel problems, we come to see them as different from or similar to known ones. Consequently, the problem situations are categorised on the basis of the laws and theories used to solve them. This kind of categorisation is at the heart of physics expertise (Chi, Feltovich \& Glaser, 1981) 
and grasping the relational structure is, by definition, at its core. This underscores the importance of learning the relevant causal structure or repertoire, as Chi et al. (2012) and Perkins and Grotzer (2005) have pointed out.

However, the meaning and representation of individual concepts cannot be extracted solely from the relational structure (Andersen \& Nersessian, 2000; Andersen et al., 2013). For example, the representation of electromagnetic field cannot be inferred only from the different problems in which it participates. To identify individual concepts, Andersen and Nersessian (2000) suggest using twolayer representation: one for the problem situations and another for the individual concepts. At the level of individual concepts, ontological status is "a belief about what kind of stuff is responsible for the particular function" (Andersen \& Nersessian, 2000, p. S235). The electromagnetic field, for example, has the ontological status "state of space" (Andersen \& Nersessian, 2000, p. S235).

The notion of ontology and its role in the student's knowledge (Chi, 2008) is comparable to the way in which Andersen and Nersessian (2000) introduce ontological status in the case of scientific theories. However, whereas Andersen and Nersessian (2000) separate the relational structure from the ontological status, Slotta and Chi (2006) do not differentiate between feature-like ("moves", "bounces") and relational qualities (e.g. interaction).

Nevertheless, on the above grounds, we argue that if we want to understand how students learn and use concepts distinguishing the level of attributes and relations is warranted. While scientific concepts have a 
definitional core provided by the relational structure, the attribute level captures the representation on the level of individual concepts.

Bridging the gap between students' conceptions and scientific concepts

A flexible, theoretically justified framework for examining students' concept learning can now be introduced by incorporating knowledge at the relational and attribute levels into a single systemic model (Koponen \& Kokkonen, 2014). This framework treats the students' conceptual structure as a connected system of different conceptual elements (to be clarified in greater detail later on). The systemic model captures the level of individual concepts by incorporating attributes in much the same way as introduced above, including the level of relational knowledge in the form of determination constructs. Determination constructs relate concepts and carry information about constraining regularities (e.g. conservation laws), which capture the essentials of causal and relational knowledge discussed above (Koponen \& Kokkonen, 2014).

The systemic model draws from theories in cognitive psychology and philosophy of science in an effort to describe students' knowledge and its development. The model allows an equally good description of the students' initial knowledge, which may be idiosyncratic and rather simple, as well as their scientific knowledge, which is complex and operates on the basis of law-like structures. In other words, the systemic model embodies both ends of the learning process and represents them as different projections of a holistic conceptual system (Koponen \& Kokkonen, 2014). 
A similar approach was used to study Finnish high school students' understanding of DC circuits, one of the main findings of which was that some of the students had undifferentiated concepts of current and voltage; they used the same attributes for both concepts (Koponen \& Huttunen, 2013). Differentiation of the concepts took place through learning theoretical, law-like (relational) knowledge. Moreover, this knowledge was achieved by incorporating the knowledge into different contexts, which strengthened the different features of the concepts (cf. Andersen et al., 2013). In this study, we examine a more advanced-level understanding in the case of university students. The context of the study, however, is the same: DC circuits. The theoretical framework based on the systemic model allows us to discern the roles of ontological shift and relational aspects of concepts in university students' understanding and learning of scientific concepts. Although the data only offer us a brief snapshot of the learning process, comparing different individuals offers valuable information about the different possible learning outcomes. 
Research questions

This study explores university students' concepts of electric current, voltage and resistance and how these concepts are connected to the use of different types of explanation models that the students construct and the types of relations between the concepts they use in constructing such models. The specific research questions are:

1. What are the different elements students use in their explanations when referring to current, voltage and resistance?

1.1 What are the attributes and constraints that students associate with current, voltage and resistance?

1.2 What are the relations that students associate with current, voltage and resistance?

2. How are the different elements connected to one another?

2.1 What kinds of explanation models do students construct?

2.2 What kinds of differences and changes are there in students' explanation models?

In answering the first research question, we selected from the data all the possible elements required to describe students' explanations. In answering the second research question, we connected the elements found in previous questions to one another and presented them as a graph (see Figure 2). The graph in Figure 2 serves as a template presenting the students' knowledge (see Figures 38) and enables comparisons and the relevant differences to be revealed in 
different stages of students' learning processes, thus also providing answers to the second research question. 


\section{Method}

Participants

The participants of the study were 31 university students studying physics. The majority of the students (20) were third- or fourth-year pre-service teachers in the Department of Physics at the University of Helsinki, Finland, who were minoring in physics (their major subject was mathematics). They had already taken their introductory physics courses and were on an intermediate-level course intended for pre-service physics teachers. Taking part in the interviews was part of this course. The rest of the students (11) were majoring in physics, attending the introductory electromagnetism course, and taking part in the interviews was voluntary. The participants consented to the use of all the data acquired and the use of pseudonyms in the results section served to protect their anonymity.

Data collection

The empirical part of this study consisted of group interviews about DC circuit problems. The interviews took place in 11 small groups (nine three-person groups, two two-person groups), except for one interview with a single interviewee (thus, there were 12 interviews). The groups consisted of either preservice teachers or first-year physics majors (no mixed groups).

In the interviews, the students were asked to perform a task in which they had to predict and explain the relative brightnesses of bulbs in different DC circuits shown in Figure 1. In choosing and planning the interview, we used similar circuits and tasks to those used by McDermott and Shaffer (1992), since 
they represent a common, well-established and well-tested way to probe students' knowledge. The students' task was as follows (note: the original task was in Finnish):

The circuits consist of similar bulbs and similar batteries. Assuming that the components are ideal (i.e., the batteries have no internal resistance), order the bulbs according to their relative brightnesses from the brightest to the dimmest. If two or more bulbs are equally bright, state this in your answer. Explain your answers.

First, the students were asked to think about their answers on their own for a few minutes. They were then asked to explain and discuss their predictions with others. Only after the students were satisfied with their predictions did they have the opportunity to test their answers with actual bulbs, wires and batteries. After they had built the circuits, they were asked to explain their observations of the relative brightnesses of the bulbs.

The purpose of the interviews was to engage the students in a free discussion with little interference from the interviewer. Thus, with no predetermined questions prepared, the interviews can be considered as unstructured or informal conversational interviews guided only by the task at hand. Two interviewers conducted all the interviews together. One of them acted as the principal interviewer while the other mainly took notes and managed the practicalities (for example videotaping, arranging the bulbs and batteries). The group interview was chosen as the interview form because it led to a more relaxed atmosphere (cf. Lewis, 1992), which evoked more natural discussion (Wilkinson, 1998), thereby eliciting a rich body of data and minimising 
interviewer bias. At the beginning of each interview, the interviewer emphasised that the students themselves were not being evaluated, so it was important that they reply frankly; and the students saw in the video that their faces were not visible. Furthermore, the participants were informed that the answers would be anonymised and used only for research purposes (that is, the course instructors would not be made aware of individual answers). Also, to avoid power imbalance situations between the interviewers and the students, which could affect the interview, the course instructors did not take part in the interviews, nor was the assignment graded.

The interviewers avoided "feeding" the terms under investigation (current, voltage or resistance) to the interviewees and were instructed to make only clarifying questions. For instance, the interviewers did not ask about electric current if the students did not use electric current in their explanations. This open-ended approach naturally posed challenges for subsequent analysis, since the students' utterances were likely to be fragmented and scattered throughout the transcript, thus requiring a lot of effort to capture the meaning of the conversation.

We also videotaped all the 12 interviews, each of which lasted on average 23 minutes (range 10 to 36 minutes). The videos show only students' hands and the table with the task sheets, and later the electric circuits. We decided to capture the students showing the circuit diagrams or electric circuits, and we supposed that the students would be more relaxed during the interview if they were not fully filmed; therefore, the students' facial expressions are absent from analysis. We transcribed the interviews verbatim. In addition, if the student 
showed something on the task sheet or from the electric circuit, we described it in the transcript.
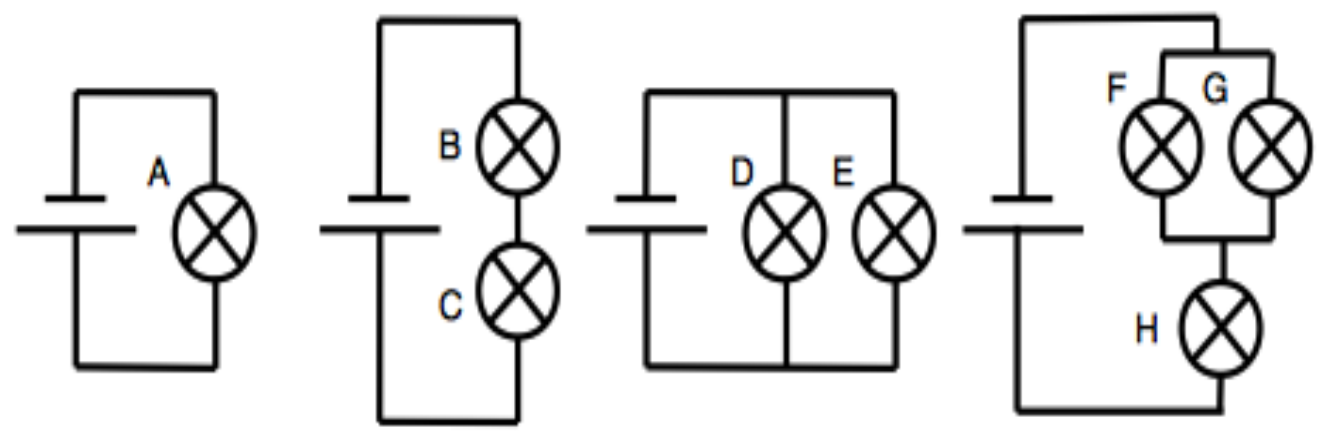

Fig 1 The circuits used in the interviews

Data analysis

We analysed the interviews by means of content analysis (cf. Chi, 1997; Elo \& Kyngäs, 2008) in order to identify the conceptual elements associated with current, voltage and resistance. As the purpose was to identify the explanation models the students used, the analysis consisted of two cycles targeting patterns at different levels (Miles, Huberman \& Saldaña, 2014; see also Chi, 1997). The analysis process can be roughly divided into four steps (cf. Chi, 1997; Elo \& Kyngäs, 2008):

1) reading the transcripts several times in order to make sense of the data as a whole,

2) condensing the essential ideas of the students' verbal expressions,

3) segmenting the condensed expressions, 
4) coding the segments.

We started the analysis process with two provisional categories (cf. Miles et al., 2014, p. 81), based on the study by Koponen and Huttunen (2013): attributes characterising the concepts and relations linking the concepts together. We then followed the principles of deductive content analysis in segmenting the data, extracting the two categories from the verbal expressions (Elo \& Kyngäs, 2008; Mayring, 2000). During the subsequent coding (step 4), three subcategories for relations and nine subcategories for attributes emerged.

Moreover, during the reading and segmenting, two more categories emerged as in inductive content analysis (Elo \& Kyngäs, 2008; Mayring, 2000): constraints and simple models. Examples of parts of the analysis described above appear in Appendix A.

After the different categories of conceptual elements emerged, we carried out a second coding cycle in order to identify the explanation models. Secondcycle coding is a way to identify "an emergent theme" or "explanation" in the data by merging categories from the first-cycle coding into meaningful patterns (Miles et al., 2014, p. 86) - in other words, coding at a larger grain size (cf. Chi, 1997). The second coding cycle was partially guided by the task. After coding the conceptual elements (concepts, attributes, relations and constraints), we identified which elements students used in explaining which features of the circuit. Typically, students focused on one particular feature of the circuit at a time (for example, comparing bulbs B and C) and took turns in explaining. We focused on these segments in the transcripts and identified the explanation models by compiling the elements (identified in the first coding cycle), which 
contributed to the explanation of the particular feature for each student. Subsequently, we drew graphs (see Figures 3-8) using these compilations, as clarified later on.

Often the students gave more or less complete explanations when it was their turn to speak but sometimes the group took shorter, conversational turns in explaining. In these cases, the students might have contributed to each other's explanations (see Appendix A: last two turns).

Subsequently, we identified eight different explanation models, which appear in the results section. Also, because the models served to explain some feature of the circuit, e.g. that "bulb A is brighter than bulb B", this aspect was also recognised from the transcript. In this way, we could identify which models served to explain which features. One model category emerged from the "simple models" category already identified during the first coding cycle. For the more complex explanation models, we categorised the models on the basis of the concepts and the relations they included.

One researcher analysed the transcripts and another researcher crosschecked one-fifth of the material. Inter-rater agreement of $70 \%$ was considered adequate. The analysts resolved all disputes through discussion.

To present the results, all the different elements - concepts, attributes, constraints, relations, explanation models and situations to be explained - were compiled into a graph (Figure 2). The graph in Figure 2 acts as a template that enables various comparisons (e.g. presenting a student's conceptual change in different stages of learning). We drew two graphs (see Figures 3-8) for each student: one from the prediction and another from the explanation phase. This 
enabled us to categorise the changes in the explanation models; consequently, we identified three types of changes, all of which are discussed in the results section. 


\section{Results}

Throughout this section, the lightbulbs are referred to with corresponding letters (presented in Figure 1) and different circuits as a combinations of letters (e.g. bulb D in circuit DE). Moreover, relative brightnesses are notated with the symbols “=” (equally bright) and ">" (brighter than).

Overview of the interviews

Of the 31 students, only three hypothesised correctly about the relative brightnesses of the bulbs. That is, they correctly predicted that $\mathrm{A}=\mathrm{D}=\mathrm{E}>\mathrm{H}>\mathrm{B}=\mathrm{C}>\mathrm{H}=\mathrm{G}$. The rest of the students were wrong in one way or another. All the students knew that bulbs in parallel connections burn equally brightly (i.e. $\mathrm{D}=\mathrm{E}$ and $\mathrm{F}=\mathrm{G}$ ), and for most students the series connection $\mathrm{BC}$ caused no problem. Seven students, however, predicted that one light bulb, either B or C, would be brighter than the other, and, in five of these cases, that either B or C would be as bright as A. Six students also thought that A, B and C would be equally bright. Similarly, predicting the correct order of $\mathrm{H}$ with respect to $\mathrm{B}$ and $\mathrm{C}$ proved to be difficult.

After building the circuits to test their predictions, 19 students were able to provide explanations for their observations. Of these, only 9 could offer more or less complete explanations; the rest could provide only partial explanations (e.g. explain the behaviour of only one circuit). So, over half of the students were unable to reconcile their knowledge with the observations contradicting their predictions. 


\section{Conceptual elements}

The first research question concerned the different features of the students' explanations - namely attributes, constraints and relations (see Table 1 and Table 2). Only the representative forms of the attributes were given: for example, a student's description that the "bulb eats up current" was classified as a use of attribute a3 (degrades, is consumed). Sometimes the concept-attribute association appeared with a certain constraint, that is, a limitation set by the geometry of the circuit (components in series or parallel) or the order in which the current or voltage met a certain bulb in the circuit (see Table 1).

Surprisingly, all but one student connected current and voltage to different attribute-constraint pairs - that is, the students differentiated the concepts at the attribute level. Notwithstanding the differentiation, students still held false beliefs that could be traced to the ontological level and appear here as certain attribute-constraint associations. For example, seven students predicted that $\mathrm{B}$ or $\mathrm{C}$ would be brighter than the other, which stems from the belief that current is somehow consumed or degraded in the circuit - a belief that has been noted in previous studies about the subject (Lee \& Law, 2001; McDermott \& Shaffer, 1992; Slotta et al., 1995). This is evident in the association of attribute a3 with current. In addition, the belief that battery is a source of constant current (McDermott \& Shaffer, 1992) was also prevalent (18 students in the prediction phase) and is represented as the association of current with attributeconstraint pair a1(c4). This became apparent, for example, in predictions that B and $\mathrm{C}$ would be as bright as A. Furthermore, seven students held that voltage 
was somehow "divided" between components in series without referring to resistance.

Our next interest was to identify the different ways in which students connected the concepts to each other. These connections, which appear in Table 2 , are called relations here, and may include causal information. The absence of relation does not, however, mean that causal information is missing. Obviously, the simplest explanations, which made no use of relations, were committed, for example, to such causal reasoning as "more current, brighter bulbs". Because the use of different relations in our study was tied to the use of different explanation models, we discuss the prevalence of each type of relation in the next section.

Table 1 Attributes, constraints and concepts with which they are associated

\begin{tabular}{|c|c|c|}
\hline Attributes & Constraints & $\begin{array}{l}\text { Associated } \\
\text { Concepts }\end{array}$ \\
\hline \multirow{3}{*}{$\begin{array}{l}\text { a1: is conserved, is the } \\
\text { same }\end{array}$} & c1: in series & \multirow[t]{3}{*}{ current, voltage } \\
\hline & c2: in parallel & \\
\hline & c4: from the battery & \\
\hline \multirow[t]{2}{*}{ a2: divides } & $\mathrm{c} 1$ : in series & \multirow[t]{2}{*}{ current, voltage } \\
\hline & c2: in parallel & \\
\hline a3: degrades, is consumed & $\begin{array}{c}\text { c3: directionally } \\
-\end{array}$ & current, voltage \\
\hline a4: flows, goes & - & current \\
\hline a5: is at a point & - & voltage \\
\hline a6: is between two points & - & voltage \\
\hline \multirow[t]{2}{*}{ a7: is larger } & c1: in series & \multirow[t]{2}{*}{ resistance } \\
\hline & c2: in parallel & \\
\hline \multirow[t]{2}{*}{ a8: is smaller } & $\mathrm{c} 1$ : in series & \multirow[t]{2}{*}{ resistance } \\
\hline & c2: in parallel & \\
\hline a9: adds up, is summed & c3: directionally & voltage \\
\hline
\end{tabular}


Table 2 Relations that connect concepts together with excerpts from the interviews

\begin{tabular}{|c|c|c|}
\hline Relation & Description & Excerpt \\
\hline r1:X -> Y & $\begin{array}{l}X \text { affects Y; Y happens because of } \\
X\end{array}$ & $\begin{array}{l}\text { "There's a bigger } \\
\text { voltage ("X")..., } \\
\text { so there's a bigger } \\
\text { current... ("Y")." }\end{array}$ \\
\hline $\begin{array}{l}\text { r2: } X->Y, \\
\text { when } Z\end{array}$ & $\begin{array}{l}\mathrm{X} \text { affects } \mathrm{Y} \text { and is moderated by } \mathrm{Z} \text {; } \\
\mathrm{Y} \text { happens because of } \mathrm{X} \text {, when } \mathrm{Z}\end{array}$ & $\begin{array}{l}\text { The voltage ("X") } \\
\text { over these bulbs is } \\
\text { the same but the } \\
\text { resistance ("Z") is } \\
\text { larger, so the } \\
\text { current ("X") is } \\
\text { smaller." }\end{array}$ \\
\hline r3: X, Y -> Z & $\begin{array}{l}\mathrm{X} \text { and } \mathrm{Y} \text { affect } \mathrm{Z} ; \mathrm{Z} \text { happens } \\
\text { because of } \mathrm{X} \text { and } \mathrm{Y}\end{array}$ & $\begin{array}{l}\text { Here, the voltage } \\
\text { ("X") is the same, } \\
\text { but the current } \\
\text { ("Z") is halved... } \\
\text { Here, the current is } \\
\text { the same, but the } \\
\text { voltage is halved." }\end{array}$ \\
\hline
\end{tabular}


Explanation models

The second coding cycle included identifying the explanation models students used. Altogether, we identified eight different types of models, which appear in Table 3. We distinguished the models according to the concepts and relations they include. The number of students using each type of explanation model appear in Table 4. The total number in the prediction row is greater than 31, because 13 students used multiple models to predict the behaviour of the circuit.

We can see from Table 4 that students favoured simple current- and resistance-based models in their explanations - that is, models which include fewer concepts and relations (M1, M2, M6 and M7). The Ohmian model (and thus relation r2) served on only five occasions in the prediction phase. The simpler explanation models M3 and M7 ("Pre-Ohmian") served on four and three occasions, respectively. 
Table 3 Descriptions of the explanation models that the students used in the interview

\begin{tabular}{|c|c|c|c|}
\hline Model & Description & $\begin{array}{l}\text { Related } \\
\text { concept(s) }\end{array}$ & Relations \\
\hline $\begin{array}{l}\text { M1 Simple } \\
\text { models }\end{array}$ & $\begin{array}{l}\text { These models are based on a } \\
\text { simple rule of thumb, such as: } \\
\text { "When the bulbs are in a series, } \\
\text { they have the same brightness." }\end{array}$ & - & - \\
\hline $\begin{array}{l}\text { M2 Current- } \\
\text { based model }\end{array}$ & $\begin{array}{l}\text { The only concept used in this } \\
\text { model is current: a current flows } \\
\text { into a circuit and causes the bulb } \\
\text { to burn. }\end{array}$ & $I$ & - \\
\hline $\begin{array}{l}\text { M3 Pre- } \\
\text { Ohmian } \\
\text { current model }\end{array}$ & $\begin{array}{l}\text { A current flowing in a circuit } \\
\text { makes the bulbs burn, and the } \\
\text { current depends on either the } \\
\text { resistance of the circuit or the } \\
\text { voltage between the ends of the } \\
\text { battery or component. }\end{array}$ & $I, R$ or $U$ & $\mathrm{r} 1$ \\
\hline $\begin{array}{l}\text { M4 Ohmian } \\
\text { model }\end{array}$ & $\begin{array}{l}\text { A current flowing in a circuit } \\
\text { makes the bulbs burn. The } \\
\text { current depends on the } \\
\text { resistance of the circuit and the } \\
\text { voltage between the ends of the } \\
\text { battery or component. }\end{array}$ & $I, R, U$ & $\mathrm{r} 2$ \\
\hline $\begin{array}{l}\text { M5 Pre- } \\
\text { electric power } \\
\text { model }\end{array}$ & $\begin{array}{l}\text { a) The brightness of the bulb } \\
\text { depends on the current running } \\
\text { through it and the voltage } \\
\text { between its ends. } \\
\text { b) The brightness of the bulb } \\
\text { depends on the current running } \\
\text { through it and the resistance of } \\
\text { the bulb. }\end{array}$ & $I, R$ or $U$ & r3 \\
\hline $\begin{array}{l}\text { M6 } \\
\text { Resistance- } \\
\text { based model }\end{array}$ & $\begin{array}{l}\text { This model uses only resistance. } \\
\text { The brightness of the bulbs is } \\
\text { determined by the resistance of } \\
\text { the bulbs and/or the resistance } \\
\text { of the circuit. }\end{array}$ & $R$ & - \\
\hline $\begin{array}{l}\text { M7 Pre- } \\
\text { Ohmian } \\
\text { voltage model }\end{array}$ & $\begin{array}{l}\text { The brightness of the bulb } \\
\text { depends on the voltage between } \\
\text { its ends. The voltage depends on } \\
\text { the resistance of the bulb. }\end{array}$ & $U, R$ & $\mathrm{r} 1$ \\
\hline $\begin{array}{l}\text { M8 Voltage- } \\
\text { based model }\end{array}$ & $\begin{array}{l}\text { This model uses only voltage. } \\
\text { The brightness of the bulb } \\
\text { depends on the voltage between } \\
\text { its ends. }\end{array}$ & $U$ & - \\
\hline
\end{tabular}


Table 4 Number of students using each explanation model in the prediction and explanation phases

\begin{tabular}{l|l|l|l|l|l|l|l|l} 
& M1 & M2 & M3 & M4 & M5 & M6 & M7 & M8 \\
\hline prediction & 9 & 18 & 5 & 5 & 2 & 4 & 3 & 5 \\
\hline explanation & 0 & 4 & 4 & 3 & 1 & 3 & 1 & 8
\end{tabular}

Representing knowledge as directed graphs

The structure of the students' conceptions of how concepts are related through different explanation models of the constraints they use in constructing the models and attributions - in brief, all the various conceptual elements relevant to the structure of students' conceptual landscapes - appear in a graph shown in Figure 2. Any of the students' specific views then appear as a partial projection of the template, as one individual student's conception shows in black lines in Figure 2. The conception of the example is that the battery is a source of electricity that the bulbs consume (see, e.g., Borges \& Gilbert, 1999; Koumaras et al., 1997; McDermott \& Shaffer, 1992). In the graph, the uppermost row denotes the feature being explained (e.g. the brightness of bulb B relative to bulb C). Incorrect explanations appear as a dashed edge. 

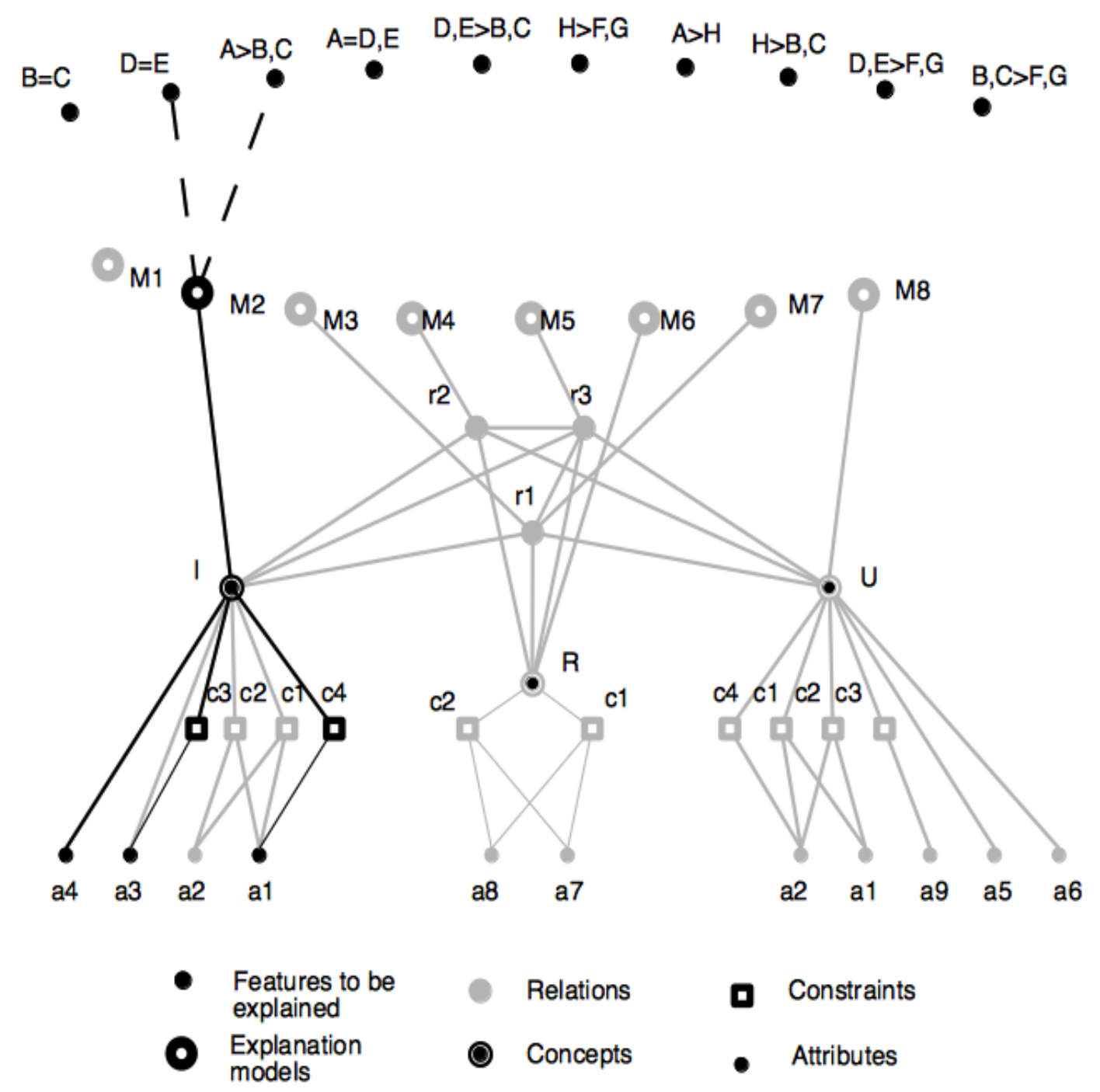

Fig 2 The template graph. An example representing the typical conception of consumption of current in the circuit appears as black lines. Possible connections between conceptual elements appear in grey.

The changes in the explanations of those students who could explain their observations differed considerably. On the whole, the types of changes observed 
fell into three categories, with one representative case selected from each category for examination in greater detail. The types are:

1) Model switch. The student abandoned the initial model used in the prediction phase in favour of another model, which shared no common features with the initial model.

2) Model elaboration. The student modified the explanation given in the prediction phase by introducing new concepts and/or relations. The models in the explanation and prediction phases shared some common concepts and/or relations.

3) Model refinement. The student could explain his or her observations with fewer models than he or she used in the prediction phase.

Of the 19 students who could somehow explain their observations, eight students fell into the model switch category, three students modified their explanation by elaborating on it and four students did so by refining it. One student fell into none of the above categories. Three students were omitted because the interviewers altered the structure of the tasks. Next, we present cases showing the different types of changes.

Model switch: James

In the rather brief prediction phase, the group in which James participated during the interview arrived at the conclusion $\mathrm{A}=\mathrm{B}=\mathrm{C}=\mathrm{H}>\mathrm{D}=\mathrm{E}=\mathrm{F}=\mathrm{G}$ regarding the brightnesses of the bulbs. Concluding that current affected brightness, James implicitly assumed that the battery acted as a source of constant current, thereby leading to incorrect predictions. Furthermore, he stated that the current 
divides at junctions (i.e. constraint c2 ("in parallel") acting on attribute a2 ("divides") in Figure 3) and that the current is the same through the bulbs connected in series (i.e. constraint $d 1$ acting on a1). This relationship is represented in Figure 3 as the activation of constraint $\mathrm{c} 4$ and attribute a1 (connected to current).

James: "There the current divides into those two... According to the principle, these two [F and G] are as bright as these two [D and E], and this $[\mathrm{H}]$ is as bright as these [B and $\mathrm{C}]$, because the current comes from there and it reunites there [after $\mathrm{G}$ and $\mathrm{H}] . "$

In the explanation phase, James first explicitly stated that it was voltage, not current, that affected the brightnesses. This is evident in the graph in Figure 4, in which only the voltage-based model (M7) is active. Echoing (but not explicitly mentioning) Kirchhoff's second law, James stated that voltage "must be used up in the circuit", which is represented as constraint c3 connected to attribute a9 in the graph.

James: "So, in a way, it has to be used... used up between here [points to $\mathrm{BC}$. If 12 goes there [A], then 6 and 6 are coming here [BC]. Right? And 12 and 12 would go there [DE]. In a way, these are treated as separate circuits [makes a loop with his finger through bulbs D and E], so that they $[\mathrm{DE}]$ would be brighter than those [BC]."

Thus, bulbs in a series were dimmer than a single bulb, but then again, bulbs in parallel were as bright as the single bulb A. James could not, however, explain why $\mathrm{F}$ and $\mathrm{G}$ were dimmer than $\mathrm{D}$ and $\mathrm{E}$. He acknowledged that 
resistance had something to do with it, but was unsure what, and even speculated that voltage is divided between bulbs connected in parallel.



Fig 3 Graph representing James's prediction phase 


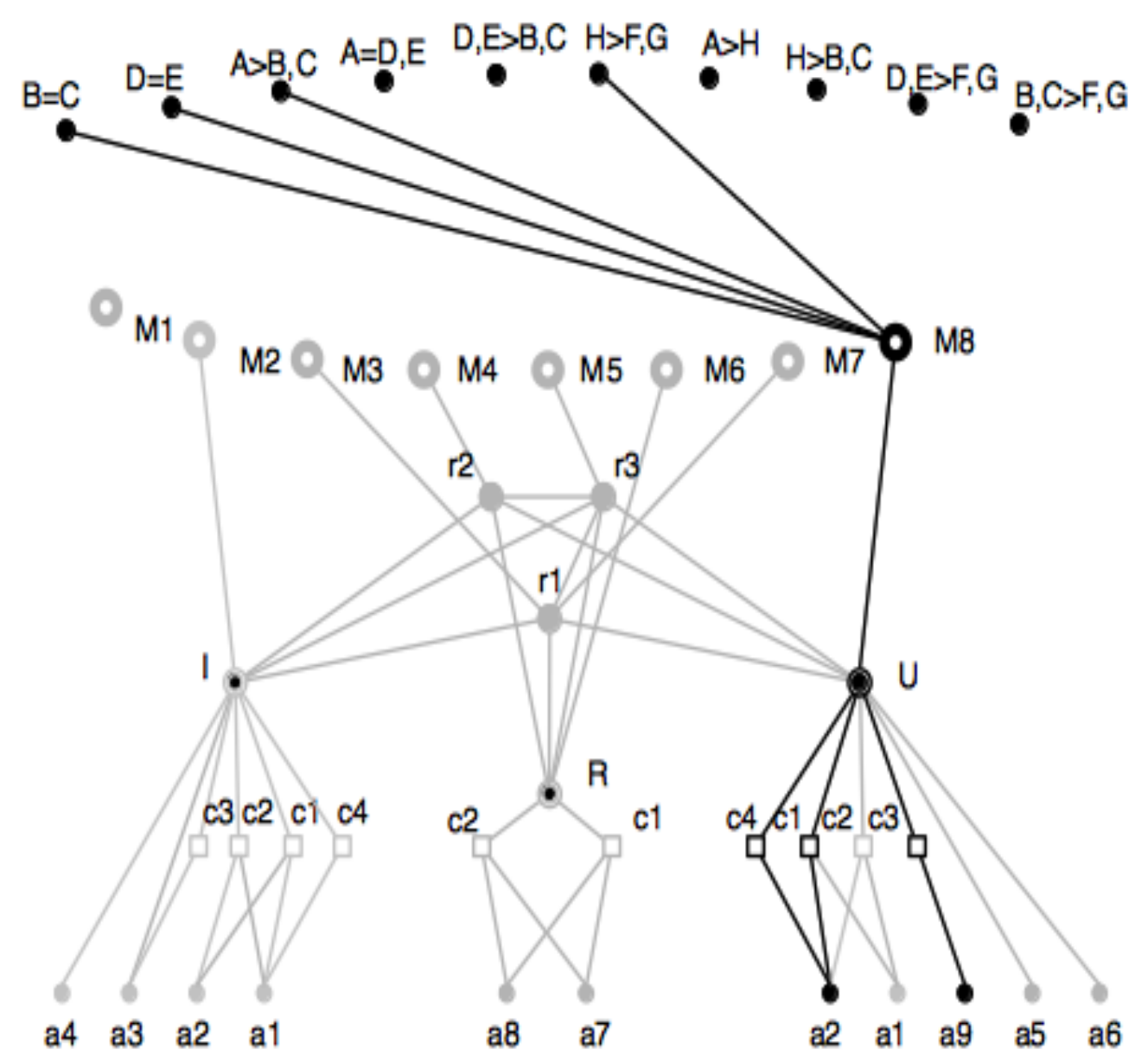

Fig 4 Graph representing James's explanation phase

Model elaboration: Daryl

In the prediction phase, Daryl explicitly referred to electric current as the flow of electrons, which goes from a positive terminal to a negative one and degrades as it goes. This is depicted in the graph in Figure 5 as attribute a3 ("degrades") being connected to the current through constraint c3 ("directionally"). Thus, Daryl assumed, for example, that B is brighter than C (and as bright as A): 
Daryl: “... electrons go from here to there [from the negative terminal to the positive one], so I would think that electricity flows from here to there...".

Interviewer: "So, on what basis is B brighter than C?"

Daryl: "Well, in a way, there's more electricity, or there's still plenty of it. Then, some of the electrons stay there [B], and after that it becomes like... when... like fewer leave towards that C."

He implicitly assumed that the battery is a source of constant current. On the other hand, Daryl first correctly predicted that A, D and E are equally bright, but offered no justifications to support these intuitions. Then, he concluded that $\mathrm{D}$ and $\mathrm{E}$ are dimmer. During the prediction phase, Daryl exclusively used current-based model M2 in his predictions.

In the explanation phase, laughter and a light-hearted discussion followed when the group members' observations contradicted their predictions. After discussing the correct ordering of the bulbs, Daryl suggested that resistance affects the brightnesses of the bulbs connected in series:

Daryl: "Or, could it just be that you only look at how many bulbs are connected in a series and their combined resistance... then it is... the resistance... so that, as if it does not matter in which order you connect the bulbs... would it go like that...?"

He used the resistance-based model (M7) to explain the series connection (BC). He then wondered why D and E were as bright as A and concluded that the battery "senses" the connection and sends more current to the DE circuit. However, at this point, he made no connection between the current and the 
resistance. Thus, he was using the current-based explanation model (M2). Finally, Daryl reasoned that there was more resistance in the BC circuit and that the current was therefore smaller. He thus made a connection between current and resistance through relation $\mathrm{r} 1$ (Figure 6) and applied the correct rule for resistance in series (attribute a7, constraint c1); according to our interpretation, he used the pre-Ohmian explanation model (M3).

Daryl: "Well, maybe in the same way the battery senses that here $[\mathrm{BC}]$ is, like, more resistance, so there, like, leaves less... current." 


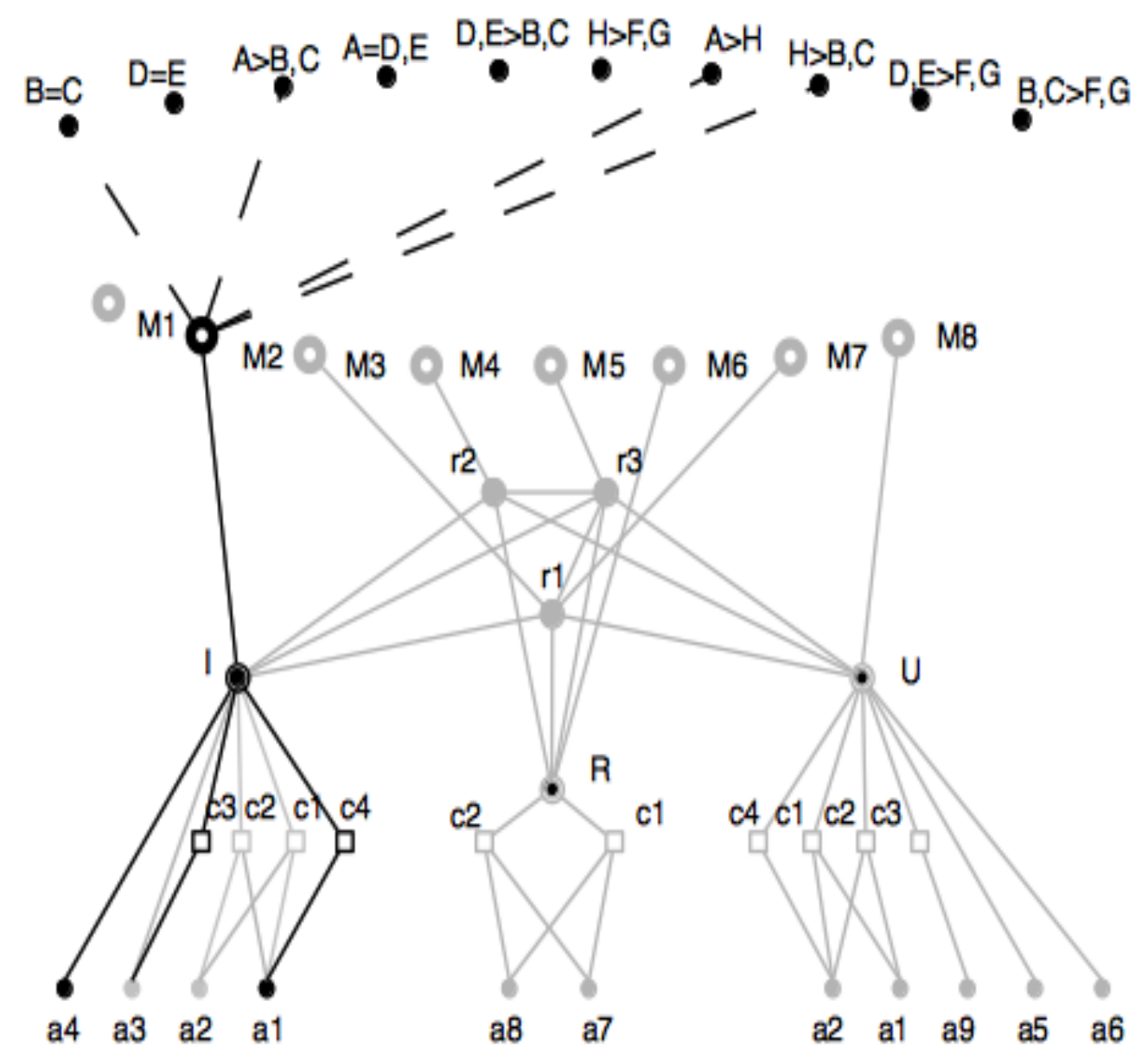

Fig 5 Graph representing Daryl's prediction phase 


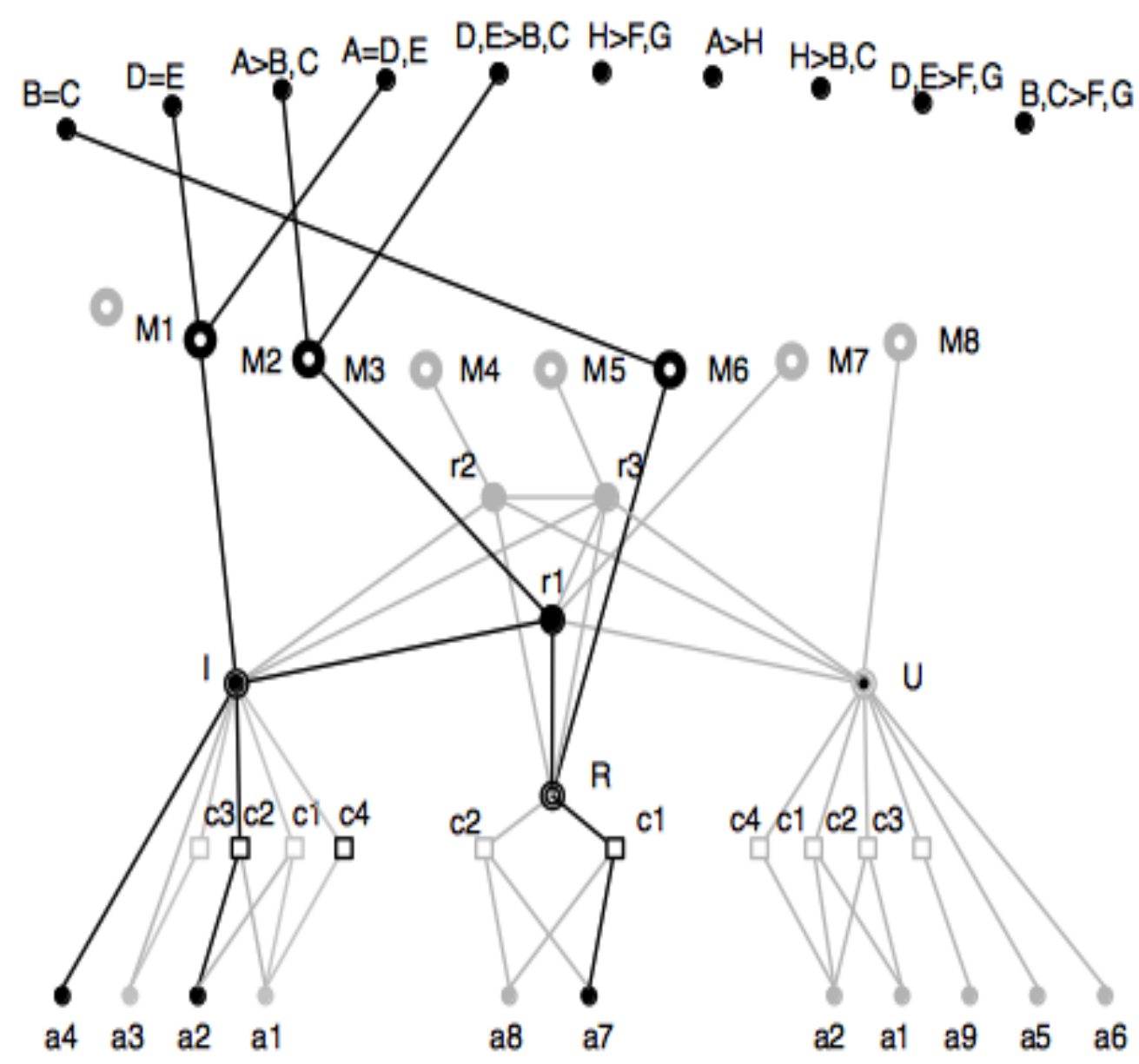

Fig 6 Graph representing Daryl's explanation phase

Model refinement: Peter

Peter's knowledge structures in the prediction and explanation phases appear in Figures 7 and 8 . In the prediction phase, he acknowledged that the bulb's resistance affects the current going through the bulb. 
Peter: "But shouldn't they be equally bright, D and E? If they're alike and resistances are equal, they have the same kind of current, because they are the same kind of bulbs...".

We identified the above model as the "pre-Ohmian" explanation model (M3), since the current was connected to resistance through relation $\mathrm{r} 1$ in the graph (Figure 7). Furthermore, current was connected to a2 (“divides") through c2 ("in parallel"). Peter then concluded that $\mathrm{D}=\mathrm{E}>\mathrm{B}=\mathrm{C}$ because the resistance of $\mathrm{DE}$ was less than the resistance of $\mathrm{BC}$. He also predicted that $\mathrm{A}=\mathrm{D}=\mathrm{E}$ but could offer no explanation for his intuition. He thus interpreted the phenomenon using the "resistance-based" explanation model, since he used no other concepts. In the graph (Figure 7), resistance is connected to a7 ("bigger") and a8 ("smaller") through c1 ("in series") and c2 ("in parallel"), respectively.

In the explanation phase, Peter concluded that the current in the branches of bulbs D and E were the same as in circuit A. He correctly used Ohm's law to reach this conclusion, depicted by the link between current, voltage and resistance, and the "Ohmian" explanation model (M4) through relation r2 in Figure 8. Regarding circuit BC, he again calculated the current in the circuit using Ohm's law:

Peter: "So here goes [D]... so... and here [circuit B and C] again the current would be like $\mathrm{U}$ over two $\mathrm{R}$, which is half of that going into these two [D and E]... Right... ?"

Peter also explained his observations with the explanation model (M4) by applying Ohm's law (r2). 


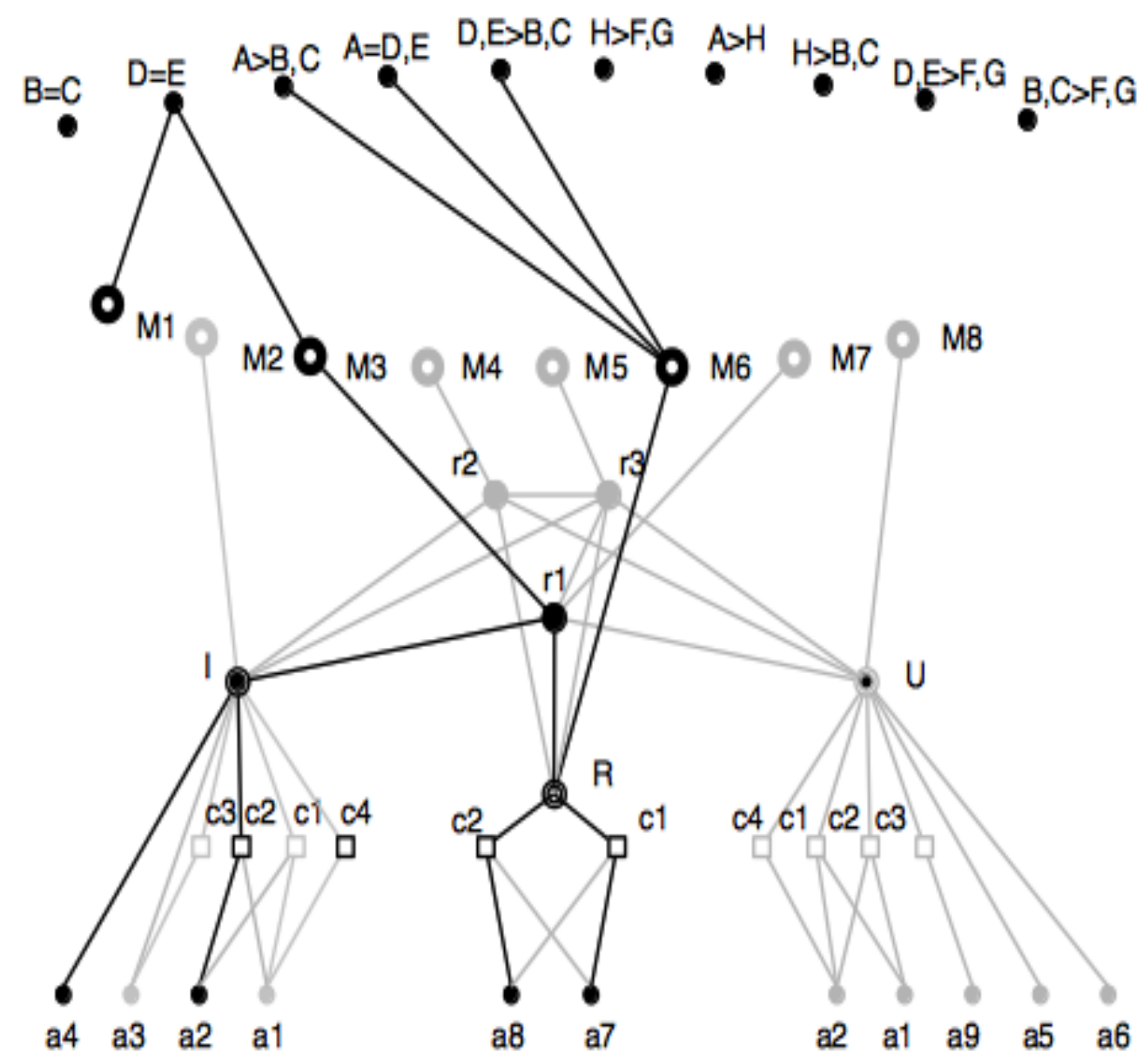

Fig 7 Graph representing Peter's prediction phase 


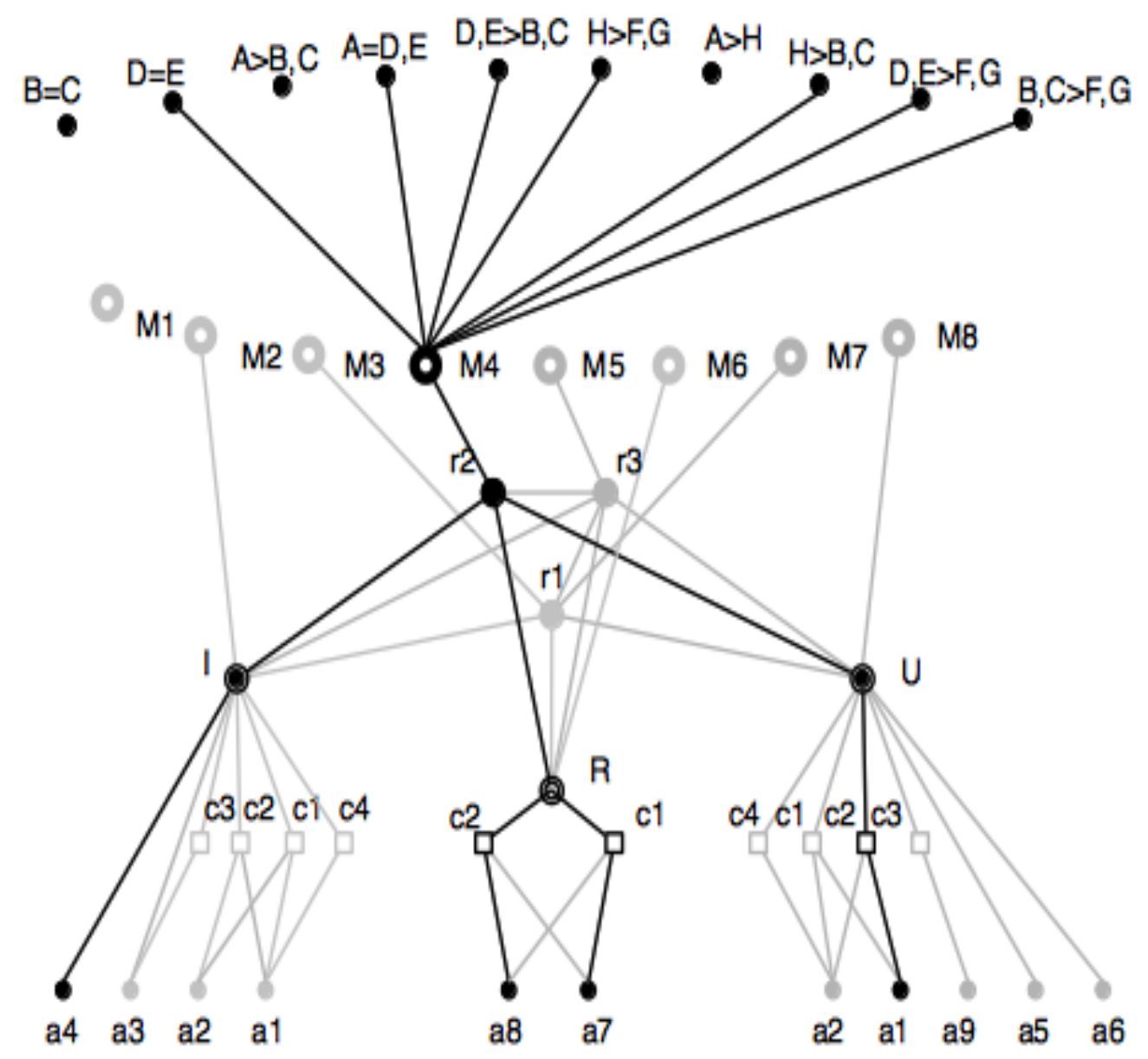

Fig 8 Graph representing Peter's explanation phase 


\section{Discussion}

In the preceding sections, we presented an analysis of students' conceptions of concepts related to DC circuit phenomena. The analysis is based on an approach that views concepts structurally, as parts of a connected system of other conceptual elements. Some of the results based on such analysis are familiar from previous research (Koponen \& Huttunen, 2013), whereas some of the findings are new or at least focused more sharply on the features that have previously received less attention.

In this section, we will evaluate the findings presented above with those of previous studies of DC circuits. We will focus on evaluating how our representation of students' conceptions compares to the findings of previous studies and how those previous findings could be interpreted within our framework. Furthermore, and perhaps more importantly, we will discuss how the concept learning process can be seen as a development of scientific knowledge wherein initially self-explanatory, naive concepts transform into complex structures dependent on other concepts.

\section{Students' conceptions}

Within our framework, students' beliefs are conceptualised as different associations of attributes and constraints with the concepts in question, as presented in the results section. It is noteworthy that in students' explanations, current and voltage were differentiated on the attribute level. This contrasts with previous studies, which have found that the terms are sometimes used interchangeably (Koponen \& Huttunen, 2013; Lee \& Law, 2001). Our analysis 
facilitated this finding, as it clarified that the concepts were connected to different sets of attributes. Further motivation for this analysis was to present the knowledge with generic elements and abstract away from the empirical details.

Notwithstanding the differentiation, many students in our study showed misconceptions also prevalent in numerous other studies on the subject of electricity. Previous studies have shown, for example, that the belief that current degrades or that current is always constant in the circuit is quite common (Koponen \& Huttunen, 2013; Lee \& Law, 2001; McDermott \& Shaffer, 1992; Shipstone, 1988; Slotta et al., 1995). It is therefore apparent that certain false beliefs are prevalent also in the case of university students. However, learning correct attributions alone is insufficient, since the relations the concepts have with other concepts also define their meaning. Although students consider voltage and current different concepts, how they differ remains unclear, as they are unrelated. Consequently, learning the relational structure is central to physics. We discuss this aspect in the data next.

Explanation models

Students relied mostly on rather simple explanation models, the current-based model appearing most frequently in the prediction phase, whereas, in the explanation phase, the voltage-based model was the most common. A similar pattern occurred elsewhere: Reiner et al. (2000) found that students rely more readily on current-based explanations, arguing that conceptions of voltage are 
less "clearly defined", which may well mean that current lends itself to concrete metaphors of, for example, "flowing" (Reiner et al., 2000, p.24).

These simple explanation models, which students relied on the most, also had a very simple causal structure. It seems that the students had difficulty in grasping the relational knowledge that ties together the concepts electric current, voltage and resistance. This result is in line with those of previous studies of students' understanding of causality or causal models, which have noted that students are predisposed towards "direct" or "linear" causality 5 and have difficulty learning, for example, emergent and constraint-based patterns (Chi et al., 2012, p.3; Perkins \& Grotzer, 2005, p.126). These results suggest that the relational nature of physics concepts causes learners great difficulties. Consequently, students' ability to apply and modify this knowledge is vital to the construction of explanation models. Our analysis focused specifically on these aspects of the students' explanation models, which seem especially important at the university level; this contrasts with those studies in which ontological shift is central.

Changes in the explanation models

As presented in the results section, 19 students could somehow explain their observations after making the predictions. Analysis of the relations students

\footnotetext{
${ }^{5}$ Linear causality refers to patterns wherein “A influences B” (Perkins \& Grotzer, 2005, p.126). Similarly, direct causality refers to patterns that can be broken into constituent simple relations (Chi et al., 2012).
} 
used revealed three novel processes that seem central to concept learning. One is the model switch, in which the model used in the explanation phase shares no common features with the model used in the prediction phase, as in the case of James. In addition, the model elaboration process emerges, as none of the initial models is capable of sufficient explanation. However, rather than simply switching the explanation model, model elaboration involves adding elements to the knowledge structure. This, of course, is crucial in constructing appropriate models for explaining physical phenomena, as the initial models rarely, if ever, are close to any scientific account. The elaboration process can be considered the first gradual step towards using relations and learning scientific knowledge.

In the model refinement process, the explanation models used in the prediction phase subsequently merge into a single type of model capable of explaining all the pertinent features of the circuits. The student may identify the relevant features of the initial or intermediate models and thus build more coherent knowledge. At this stage, the student already possesses fairly elaborate knowledge, which enables him or her to combine parts of it into a single explanation model. The different processes appear in Figure 9, where the different changes also appear in the order in which they appear in our data. This suggests a specific progression through the successive explanation models. 


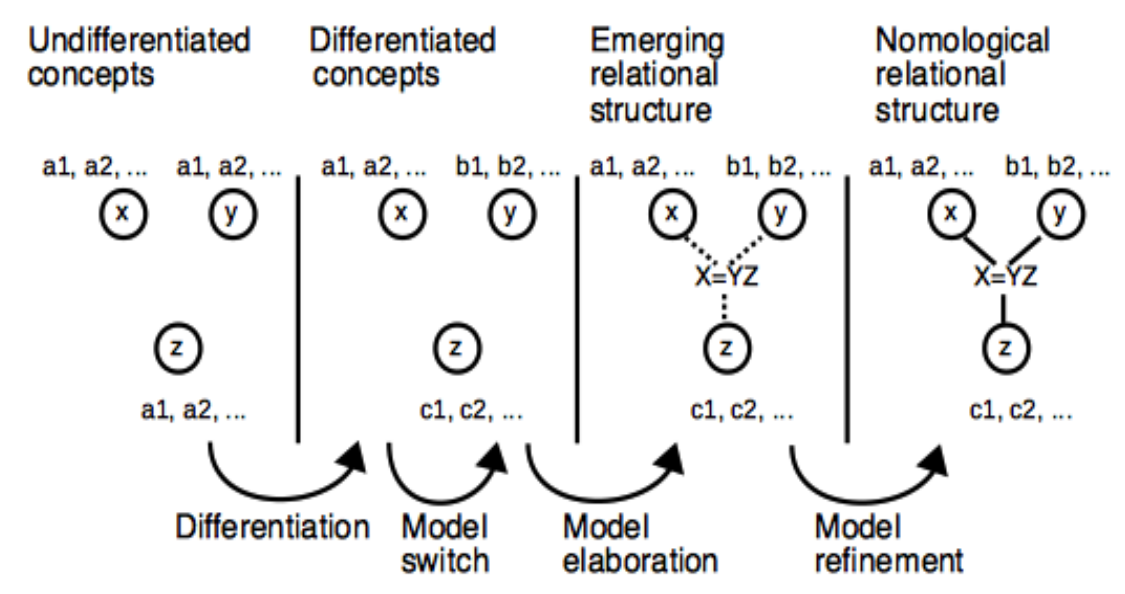

Fig 9 Model changes. $\mathrm{X}, \mathrm{Y}$ and $\mathrm{Z}$ denote concepts and a1, b1,... denote attributes.

Therefore, while our results align with those of previous research, which described students' knowledge in terms of their causal and relational structures, we extend the previous works by proposing specific learning processes involved in the construction of explanation models. Our results provide identifiable successive development steps between different types of models. ${ }^{6}$

Moreover, they do so by virtue of analysing and presenting the data within the systemic view, which considers the generic elements and their interdependencies important. In this respect, the present work also extends the work of Koponen and Huttunen (2013) by conducting the research in the context of university students, in which the differentiation on the attribute level had already taken place and the focus was more sharply on relational knowledge.

\footnotetext{
${ }^{6}$ Related descriptions include Clement's (2002) intermediate models and the learning paths proposed by Duschl et al. (2011).
} 
Because of the changes in the explanation models, the understanding of each concept's meaning changes as they are assigned certain roles in the subsequent relational structure (cf. Andersen et al., 2013; Hoyningen-Huene, 1993; Kuhn, 2012). Moreover, complete differentiation of closely related concepts requires comprehension of the relevant relational structure. Only when concepts are used in a law-like, relational structure are their meanings and roles unambiguously defined and understood as different concepts.

In addition, our results and analysis link cognitive aspects of the concept learning process to the dynamic frames view of scientific concepts (cf. Andersen et al., 2013), thereby clarifying how concepts are identified and how relational knowledge as well as the context-dependent dynamics of the learning process contribute to the meaning and learning of scientific concepts.

\section{Conclusions and implications}

Our analysis of students' interviews reveals that many students lacked the relevant relational knowledge they needed to explain DC circuit phenomena. However, some students were able to modify their explanation models during the interview. Regarding the changes, our analysis suggests three distinct types of changes in students' explanation models: model switch, model elaboration and model refinement. Model elaboration and refinement in particular reflect changes in the relational structure of the explanations.

Furthermore, our paper contributes to discussions of concept learning in a context in which the ontological shift has already taken place. While the lack of relevant relations aligns well with the previous literature, we also found that 
students' concepts were differentiated. This suggests that, in higher learning, learning can be attributed to greater proficiency in using theoretical knowledge. This also suggests that initial differentiation precedes the learning of relations. In other words, students should be able to individuate the concepts at the ontological level before assigning relations to them. Another possibility could be that certain relational information would invite particular attributes at the ontological level. This, of course, is an empirical question, which establishes an interesting setting for future research.

We have emphasised the importance of relational knowledge and its role in the development of scientific knowledge. As for the educational implications, previous studies indeed suggest that direct instruction about the different causal schemes enhances learning (Perkins \& Grotzer, 2005; Slotta \& Chi, 2006). Likewise, the proposed benefit of using analogies in physics education underscores this, as their power lies in the mapping of the relational structure. Moreover, the causal structure lies at the heart of analyses of the structure of scientific theories and their development.

Overall, the framework presented here seems well suited to analysing students' knowledge. This offers a way to further illuminate, for example, the process of concept learning by capturing the essential elements that make up the targeted knowledge structure. 
Limitations of the current study

The data and results we have presented are focused on university students' learning in the context of DC circuits. As such, the specific results about students' conceptions may not be generalisable to other contexts, and different teaching approaches may give rise to different learning processes. In particular, such cases as presented in Koponen and Huttunen (2013), in which students still had undifferentiated concepts, may differ from the cases presented here. Moreover, as the data are qualitative, they do not permit definitive conclusions about the learning processes. Nonetheless, the contribution is to propose grounded hypotheses about the learning processes (cf. Clement \& Steinberg, 2002).

\section{References}

Amin, T. G., Smith, C. L., \& Wiser, M. (2014). Student conceptions and conceptual change. In N. G. Lederman, \& S. K. Abell (Eds.), Handbook of research on science education (vol. 2) (pp. 57-81). New York, NY: Routledge.

Andersen, H., Barker, P., \& Xiang, C. (2013). The cognitive structure of scientific revolutions. Cambridge: Cambridge University Press. 
Andersen, H., \& Nersessian, N. J. (2000). Nomic concepts, frames, and conceptual change. Philosophy of Science, 67, S224-S241.

Borges, A. T., \& Gilbert, J. K. (1999). Mental models of electricity. International Journal of Science Education, 21(1), 95-117.

Brown, D. E., \& Hammer, D. (2008). Conceptual change in physics. In S. Vosniadou (Ed.), International handbook of research on conceptual change (pp. 127-154). New York, NY: Routledge.

Chi, M. T. (1997). Quantifying qualitative analyses of verbal data: A practical guide. The Journal of the Learning Sciences, 6(3), 271-315.

Chi, M. T. (2008). Three types of conceptual change: Belief revision, mental model transformation, and categorical shift. In S. Vosniadou (Ed.), International Handbook of Research on Conceptual Change (pp. 61-82). New York, NY: Routledge.

Chi, M. T. (2013). Two kinds and four sub-types of misconceived knowledge, ways to change it and the learning outcomes. In S. Vosniadou (Ed.), International handbook of research on conceptual change (2nd ed., pp. 49-70). London: Routledge.

Chi, M. T., Feltovich, P. J., \& Glaser, R. (1981). Categorization and representation of physics problems by experts and novices*. Cognitive Science, 5(2), 121-152.

Chi, M. T., Roscoe, R. D., Slotta, J. D., Roy, M., \& Chase, C. C. (2012). Misconceived causal explanations for emergent processes. Cognitive Science, $36(1), 1-61$. 
Chi, M. T., Slotta, J. D., \& De Leeuw, N. (1994). From things to processes: A theory of conceptual change for learning science concepts. Learning and Instruction, 4(1), 27-43.

Clement, J. J., \& Steinberg, M. S. (2002). Step-wise evolution of mental models of electric Circuits: A" learning-aloud" case study. The Journal of the Learning Sciences, 11(4), 389-452.

De Bock, D., Van Dooren, W., \& Verschaffel, L. (2011). Students' overuse of linearity: An exploration in physics. Research in Science Education, 41(3), $389-412$.

Duschl, R., Maeng, S., \& Sezen, A. (2011). Learning progressions and teaching sequences: A review and analysis. Studies in Science Education, 47(2), 123182.

Elo, S., \& Kyngäs, H. (2008). The qualitative content analysis process. Journal of Advanced Nursing, 62(1), 107-115.

Gupta, A., Hammer, D., \& Redish, E. F. (2010). The case for dynamic models of learners' ontologies in physics. The Journal of the Learning Sciences, 19(3), 285-321.

Hoyningen-Huene, P. (1993). Reconstructing scientific revolutions: Thomas $S$. Kuhn's philosophy of science. Chicago, Ill: University of Chicago Press.

Koponen, I. T., \& Huttunen, L. (2013). Concept development in learning physics: The case of electric current and voltage revisited. Science \& Education, 22(9), $2227-2254$.

Koponen, I. T., \& Kokkonen, T. (2014). A systemic view of the learning and differentiation of scientific concepts: The case of electric current and voltage 
revisited. Frontline Learning Research, 2(3), 140-166.

http://dx.doi.org/10.14786/flr.v2i2.120

Koumaras, P., Kariotoglou, P., \& Psillos, D. (1997). Causal structures and counter - intuitive experiments in electricity. International Journal of Science Education, 19(6), 617-630.

Kuhn, T. S. (2012). The structure of scientific revolutions (4th ed.). Chicago, Ill: University of Chicago Press.

Lee, Y., \& Law, N. (2001). Explorations in promoting conceptual change in electrical concepts via ontological category shift. International Journal of Science Education, 23(2), 111-149.

Lewis, A. (1992). Group child interviews as a research tool. British Educational Research Journal, 18(4), 413.

Mayring, P. (2000). Qualitative content analysis. Forum Qualitative Sozialforschung / Forum: Qualitative Social Research, 1(2). http://nbnresolving.de/urn:nbn:de:0114-fqs0002204.

McDermott, L. C., \& Shaffer, P. S. (1992). Research as a guide for curriculum development: An example from introductory electricity. part I: Investigation of student understanding. American Journal of Physics, 60, 994-994.

Miles, M. B., Huberman, M. A., \& Saldaña, J. (2014). Qualitative data analysis: A methods sourcebook (3rd ed.). Los Angeles, CA: SAGE Publications.

Nersessian, N. J. (1995). Should physicists preach what they practice? Science \& Education, 4(3), 203-226.

Nersessian, N. J. (2008). Creating scientific concepts. Cambridge, MA: The MIT Press. 
Perkins, D. N., \& Grotzer, T. A. (2005). Dimensions of causal understanding: The role of complex causal models in students' understanding of science. Studies in Science Education, 41(1), 117-165.

Reiner, M., Slotta, J. D., Chi, M. T., \& Resnick, L. B. (2000). Naive physics reasoning: A commitment to substance-based conceptions. Cognition and Instruction, 18(1), 1-34.

Shipstone, D. (1988). Pupils' understanding of simple electrical circuits. some implications for instruction. Physics Education, 23(2), 92.

Slotta, J. D., \& Chi, M. T. (2006). Helping students understand challenging topics in science through ontology training. Cognition and Instruction, 24(2), 261-289.

Slotta, J. D., Chi, M. T., \& Joram, E. (1995). Assessing students' misclassifications of physics concepts: An ontological basis for conceptual change. Cognition and Instruction, 13(3), 373-400.

Smith, C., Carey, S., \& Wiser, M. (1985). On differentiation: A case study of the development of the concepts of size, weight, and density. Cognition, 21(3), 177-237.

Vosniadou, S. (2002). On the nature of naïve physics. In Limón, M. \& Mason, L. (Eds.), Reconsidering conceptual change: Issues in theory and practice (pp. 61-76). New York, NY: Kluwer Academic Publishers.

Vosniadou, S., \& Skopeliti, I. (2014). Conceptual change from the framework theory side of the fence. Science \& Education, 23(7), 1427-1445.

Wilkinson, S. (1998). Focus group methodology: A review. International Journal of Social Research Methodology, 1(3), 181-203. 
Wiser, M., \& Amin, T. (2001). "Is heat hot?" inducing conceptual change by integrating everyday and scientific perspectives on thermal phenomena. Learning and Instruction, 11(4), 331-355 


\section{Appendix A}

\section{Excerpt From the Analysis of Students 21 and 22}

\begin{tabular}{|c|c|c|c|}
\hline Transcribed text & Condensed & Relations & Attributes (constraints) \\
\hline $\begin{array}{l}\text { Interviewer: "So, they are equally bright. } \\
\text { But, why does the same current that goes } \\
\text { here [bulb A] also go here [D and E]...?" }\end{array}$ & & & \\
\hline $\begin{array}{l}\text { Student 21: "Is it due to the voltage } \\
\text { difference, since the voltage difference here } \\
\text { [over D and E] is the same, and they have } \\
\text { the same resistance, and that's why same } \\
\text { current goes in there?" }\end{array}$ & $\begin{array}{l}\text { A, D, and } \mathrm{E} \text { have the } \\
\text { same voltage and the } \\
\text { same resistances, so the } \\
\text { same current goes } \\
\text { through both of them. }\end{array}$ & R2: U $\rightarrow$ I, when R & $\begin{array}{c}\text { i4 } \\
\text { u1(c2) } \\
\text { u1(c4) }\end{array}$ \\
\hline
\end{tabular}




\begin{tabular}{|c|c|c|c|}
\hline & $\begin{array}{l}\text { The same voltage comes } \\
\text { from the battery. }\end{array}$ & & \\
\hline \multicolumn{4}{|l|}{$\begin{array}{l}\text { Interviewer: "So, how would you explain } \\
\text { the next one [circuit BC]?" }\end{array}$} \\
\hline $\begin{array}{l}\text { Student 21: "Well, the same voltage that's } \\
\text { here [over bulbs B and C]...is also between } \\
\text { here. So, the voltage decreases... or } \\
\text { potential." }\end{array}$ & $\begin{array}{l}\text { The voltage is divided in } \\
\text { the series. The battery } \\
\text { provides the same } \\
\text { voltage. }\end{array}$ & & $\begin{array}{l}\mathrm{u} 2(\mathrm{c} 1) \\
\mathrm{u} 1(\mathrm{c} 4)\end{array}$ \\
\hline $\begin{array}{l}\text { Student 22: "So, the resistance is double } \\
\text { because they are in a series" }\end{array}$ & $\begin{array}{l}\text { Resistance is greater in } \\
\text { a series. }\end{array}$ & & $\mathrm{r} 7(\mathrm{c} 1)$ \\
\hline Student 21: "So, the current halves." & $\begin{array}{l}\text { The greater the } \\
\text { resistance, the lower the } \\
\text { current. }\end{array}$ & $\mathrm{R} 1: 1 / \mathrm{R} \rightarrow \mathrm{I}$ & \\
\hline
\end{tabular}


STUDENTS' EXPLANATION MODELS 